\title{
Role of priority setting in implementing universal health coverage
}

\author{
Explicit, evidence based priorities are essential for efficient use of resources
}

\author{
Yot Teerawattananon programme leader ${ }^{1}$, Alia Luz project associate ${ }^{2}$, Churnrurtai Kanchanachitra \\ director, Mahidol University Global Health ${ }^{3}$, Sripen Tantivess senior researcher ${ }^{1}$, On behalf of the \\ Prince Mahidol Award Conference secretariat
}

\author{
${ }^{1}$ Health Intervention and Technology Assessment Program (HITAP), Thailand; ${ }^{2}$ HITAP International Unit, Ministry of Public Health, Mueang, \\ Nonthaburi 11000 , Thailand; ${ }^{3}$ Mahidol University, Salaya, Thailand
}

\begin{abstract}
When is a country financially ready to implement universal health coverage (UHC), a health policy designed to ensure that all citizens receive the health services they need without financial hardship? ${ }^{1}$ Since no standard set of essential health services or a defined benefits package for universal coverage exists, determining financial readiness is challenging. Health priorities must be set knowing what services are to be provided, to whom they will be provided, and how.

Priority setting helps determine the financial requirements for UHC, and thus the financial capacity of a country to adopt it. Setting priorities also helps decide on the benefits package that is feasible given current resource constraints. Countries can deliver a limited benefits package and identify priorities for expansion should additional resources become available. In either scenario, priority setting is essential for any country committed to universal coverage.
\end{abstract}

Priority setting can be explicit or implicit. Governments should favour explicit rationing, wherein the decisions and their justifications are clear, rather than strategies of implicit rationing such as denial, deterrence, deflection, delay, and dilution. ${ }^{2}$ In 2015, the UN General Assembly made a global commitment to UHC and the sustainable development goals. ${ }^{34}$ As such, more emerging economies will commit to UHC. Explicit priority setting, however, requires dedicated resources, which are more readily available in wealthier countries.

In 1912, Norway was the first country to introduce UHC. Several other high income countries followed, but 64 years passed before Cuba became the first middle income country to introduce UHC legislation in 1976. By 2015, 58 countries had achieved universal coverage, of which 22 did so while they were low or middle income countries (LMICs). ${ }^{5}$ Thus, the challenge that remains is supporting countries with limited capacity to implement UHC and set priorities explicitly.

Health priority setting in support of UHC requires capacity and resources, as well as persuasive evidence to justify decisions (figure). ${ }^{6}$ This involves two major steps: evidence generation and use of evidence in resource allocation, programme management, and quality assurance. Priority setting in health systems is complicated by a wide range of political, economic, ethical, and sociocultural factors. ${ }^{7}$ An explicit process requires four building blocks (box).

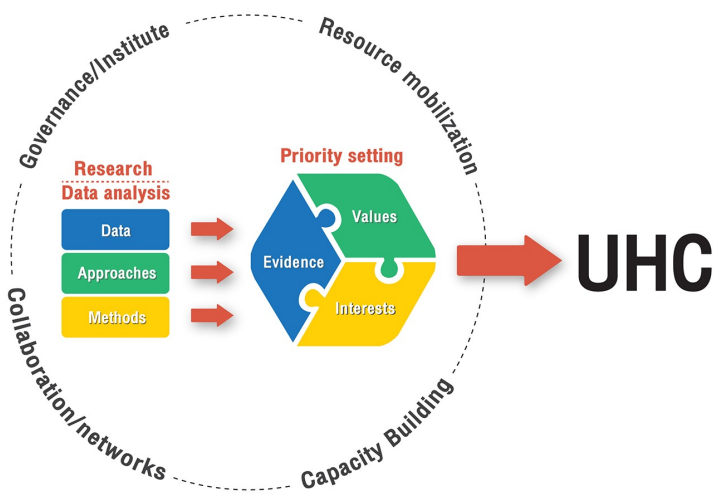

Framework for evidence informed priority setting

Evidence generation, either from academically rigorous research or from relatively simpler analyses of data, requires skilled workers, reliable and up-to-date data and information systems, rigorous methods, and pragmatic approaches. For example, health technology assessment is recognised as a useful tool for setting priorities for biomedical and public health interventions. ${ }^{8}$ But generation of evidence does not guarantee it will be acted on. The connection between evidence, priority setting, and policy making is influenced by politics and shaped by social values such as efficiency, equity, morality, and solidarity as well as various competing interests ${ }^{9}$ - for example, those of 


\section{Four building blocks for effective priority setting}

- Governing structure with clear functions and regulation of institutes and their inter-relations

- Resource availability and mobilisation to support priority setting

- Capacity building programmes for better understanding of health priority setting by policy makers, researchers, and other stakeholders, including the general public

- Collaboration with networks of local, international, and global organisations that aim to support UHC policies.

society, health purchasers, providers, professionals, drug companies, and device manufacturers. ${ }^{10}$

In practice, setting health priorities in most LMICs is imperfect because of constraints in the four building blocks. Importantly, inadequate governance impairs resources, system capacity, and support from other organisations. These issues allow powerful vested interests, such as industry and health professionals, ${ }^{11}{ }^{12}$ to dominate both the technical and political aspects of priority setting. Subsequently, the quality of evidence is undermined, as is political commitment to using evidence to inform decision making, disinvestment, programme design, and formulation of guidelines for UHC. ${ }^{13}$

UHC is not only about financial readiness; it also requires good governance in allocating finite resources and ensuring health and equity. The Prince Mahidol Award Conference on 26-31 January 2016, in Bangkok, Thailand, will discuss the Bangkok statement, which aims to garner commitment and provide guidance to develop fair, transparent, systematic, and evidence based priority setting processes to support achievement of the goals of UHC. We welcome your comments on our draft proposals available at the conference website (www. pmaconference.mahidol.ac.th/index.php?option=com_content\& view $=$ article $\& i d=758 \&$ Itemid).

Sufficient finances have the potential to improve infrastructure, provision of health services, and availability of human resources, but they do not guarantee good governance and efficient use of resources. This is the important role of priority setting in implementing universal health coverage.

Competing interests: We have read and understood BMJ policy on declaration of interests and declare the following: CK is part of the conference secretariat, and HITAP works as a technical lead for the planning of the conference. However, the authors did not have financial support for writing this editorial. HITAP's International Unit was established with support from the Thai Health-Global Link Initiative Project (TGLIP), the international Decision Support Initiative (iDSI) funded by the Bill and Melinda Gates Foundation and the UK Department of International Development, and the Rockefeller Foundation to provide technical assistance on health intervention and technology assessment for governments of low and middle income countries. The editorial does not necessarily reflect the views of these agencies.

Provenance and peer review: Commissioned; not externally peer reviewed.

WHO. Health systems financing: the path to universal coverage. WHO, 2010.

2 Klein RDP, Redmayne S. Managing scarcity: priority setting and rationing in the NHS Open University Press, 1996

3 General Assembly Resolution 67/81. Global health and foreign policy, A/Res/67/81 (12 December 2012). www.un.org/en/ga/search/view_doc.asp?symbol=A/RES/67/81.

4 United Nations General Assembly. Draft outcome document of the United Nations summit for the adoption of the post-2015 development agenda, A/69/L.85, 12 August 2015. www. un.org/ga/search/view_doc.asp?symbol=A/69/L.85\&Lang=E.

5 Stuckler D, Feigl A, Basu S, McKee M. The political economy of universal health coverage. Background paper for the global symposium on health systems research. WHO, 2010.

6 WHO. Health intervention and technology assessment in support of universal health coverage: agenda item 15.7. 2014. http://apps.who.int/gb/ebwha/pdf_files/WHA67/A67 R23-en.pdf.

7 Clark S, Weale A. Social values in health priority setting: a conceptual framework. J Health Organ Manage 2012;26:293-316.

8 Mohara A, Youngkong S, Velasco RP, et al. Using health technology assessment for informing coverage decisions in Thailand. J Comp Eff Res 2012;1:137-46.

9 Tantivess S, Perez Velasco R, Yothasamut J, Mohara A, Limprayoonyong $\mathrm{H}$, Teerawattananon $\mathrm{Y}$. Efficiency or equity: value judgments in coverage decisions in Thailand. $J$ Health Organ Manage 2012;26:331-42.

10 Drummond M, Tarricone R, Torbica A. Assessing the added value of health technologies: reconciling different perspectives. Value in Health 2012;16:S7-13.

11 Bishop D, Lexchin J. Politics and its intersection with coverage with evidence development: a qualitative analysis from expert interviews. BMC Health Serv Res 2013;13:88.

12 Ulucanlar S, Faulkner A, Peirce S, Elwyn G. Technology identity: the role of sociotechnical representations in the adoption of medical devices. Soc Sci Med 2013;98:95-105.

13 Chootipongchaivat S, Tritasavit N, Luz A, Teerawattananon Y, Tantivess S. Factors conducive to the development of health technology assessment in Asia: impacts and policy options. 2015. http://iris.wpro.who.int/handle/10665.1/12588. 